Wren Strabucchi

\section{El último monumento}

Siguiendo el modus operandi de la Antigua Roma, Mussolini transformó al edificio y la ciudad como el La relación que ésta estableció con la arquitectura moderna, baciéndola ocupar un sitial estético tradicionalmente ocupado por la arquitectura clásica, es el tema planteado por este artículo derivado de una tesis doctoral. Palabras clave: Arquitectura-Italia-siglo XX, arquitectura fascista, EUR, Palabras clave:
monumento.

According to the modus operandi of ancient Rome, Mussolini transformed buildings and the city as the materialized body of the Fascist ideology. This article, derived from a doctoral dissertation, examines bis relations with contemporary architecture, which be granted a place traditionally occupied by Classical architecture.

Keywords: Architecture-ltaly-20th century, fascist architecture, EUR, cuerpo materializado del avance de la ideología fascista.

\section{Aclaraciones previas}

Este escrito es un extracto del prefacio de la tesis. Este extracto no ejemplifica y no desarrolla el argumento pero presenta la óptica bajo la cual se estudió la arquitectura italiana de entre guerras $y$, más especificamente, una de las obras más ambiciosas del período fascista italiano: la ciudad de EUR.

Un punto importante de aclarar es que no soy bijo de aquellas guerras, todo lo contrario, soy un burgués que estudió este periodo desde latitudes opuestas, si bien viví mi juventud bajo un régimen no democrático. Digo esto porque después de la guerra, y con justa razón, el odio hacia este período era el lente desde el cual se juzgaba. Por tanto esta ciudad ideada y planificada y en parte construida durante este período presentó el blanco perfecto para todo disparo de repugnancia. No tengo esa pasión; sin embargo siento una enorme empatía hacia ella ${ }^{1}$.

Aun estando las cosas así, me parece que el caso estudiado plantea cuestiones centrales de nuestra cultura y del debate arquitectónico actual. El escrito busca comprender este período y su arquitectura. Está dentro de esa comprensión el juicio. Subyace al escrito el reconocimiento, ejemplificado con un caso, que por debajo de las diferencias estilísticas bay elementos estructurales que suponen que el fascismo es un resultado de condiciones exacerbadas de la modernidad o que nuestra cultura moderna conlleva condiciones totalitarias.

Cultura como cuadro y proyecto: la ciudad de EUR. La formación del concepto ciudad-museo en la arquitectura italiana de los años ' $\mathbf{3 0}$.

$\mathrm{La}$ arquitectura italiana entre las dos guerras es generalmente clasificada, aún hoy, bajo categorías estilístico-formales: "tradicionalista" (académica), moderada (estilo littorio) y modernista (racionalista), minimizando cuanto de la ideología política había influenciado la arquitectura de este
1Sobre la interpretación de la ver p. 4 de la tesis.

(n) 2 Le Corbusier, Hacia una arquitectura Poseidón, Buenos Aires, 1964, p. 124 3 Ghirardo, Diana Yvonne, «ttalian Architecture and Fascist Politics: An Evaluation of Rationalist's Role in of Architecturat
pp. $109-127$. arquitectura de este perído de desde el fascismo hasta la actualidad, Regime Building", Journal of the Socie
of Architectural Historians no 39,1980 ,
Bruno Zevi sugiere que la de la arquitectura taliana es un microcosmos del movimiento moderno europeo, sin embargo no extiende el argumento. Zevi, Bruno, Storia dell arquitectura moderna, Enaud 5 Manuscrito de Terragni publicado por primera vez en el libro Schumacher, Thomas, II Danteum de Terragni 1938, período. La arquitectura fascista italiana es fácilmente descartada por bombástica, tiránica $y$, tal como la política fascista, es considerada como algo que no podría pasar en una "sociedad libre". Consideremos, sin embargo, la siguiente apología por los antiguos romanos como constructores y empresarios de un imperio:

"Roma se dedicó a conquistar y gobernar el mundo. Estrategia, reclutamiento, legislación: el espíritu de orden. (...) El orden Romano es un orden sencillo, categórico. Si es brutal, tanto peor"'.

Por cuanto estas palabras podrían haber sido proclamadas por Mussolini en uno de sus discursos, es en realidad Le Corbusier quien las escribió en Hacia una Arquitectura. Por mucho que esta comparación pueda parecer un tanto equívoca, refleja un modo de pensar de la época. Efectivamente, una preocupación central para ambos (Mussolini y Le Corbusier) era lograr "orden": orden arquitectónico para Le Corbusier, orden político para Mussolini, y orden social para los $\operatorname{dos}^{3}$. Le Corbusier muestra el alcance por el cual cree que la arquitectura y la política están relacionadas en sus famosas últimas palabras de Hacia una Arquitectura: "Arquitectura o Revolución". Es cierto que Le Corbusier tenía su propia fascinación con los temas del poder; pero es raramente considerado un arquitecto fascista. Esto nos debería alertar hacia lo inadecuado del término "fascismo" en su aplicación en arquitectura, pero, más significativamente, a la posible continuidad entre la arquitectura denominada fascista y el resto de la arquitectura moderna ${ }^{4}$.

Como sucede, la clave a este problema no yace en separar la política de la arquitectura, una estrategia de aquellos críticos que buscan mantener la credibilidad democrática de arquitectos como Terragni. Una lectura breve de sus Relazione sul Danteum $^{5}$ no deja dudas de las creencias de
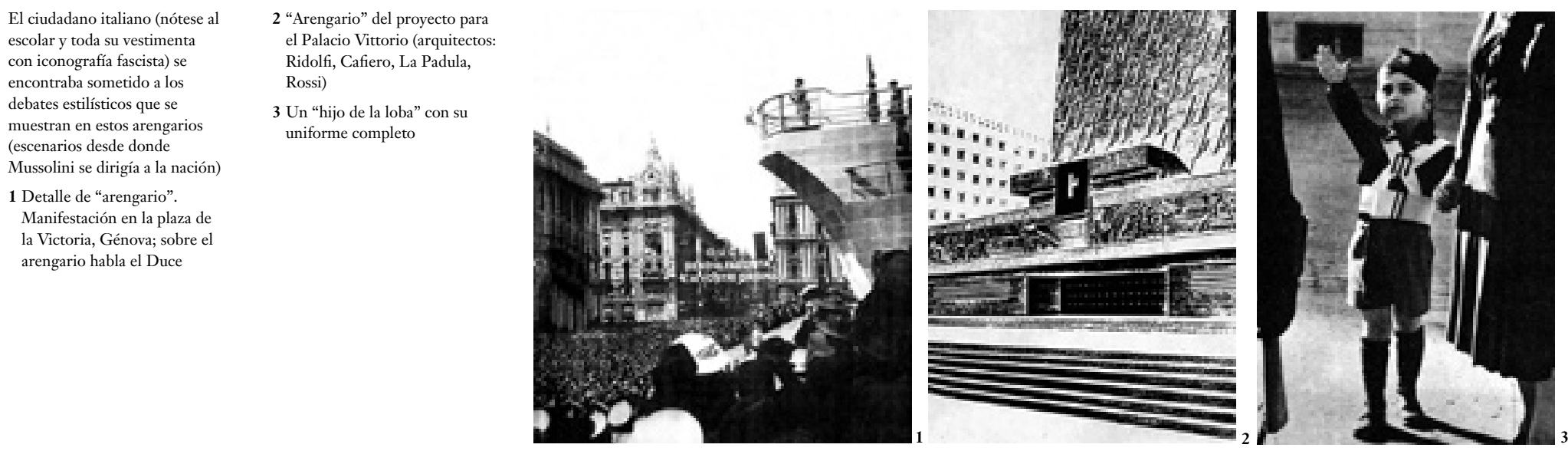


\section{'La influencia e importancia de categorías $\quad{ }^{\circ}$ En Critica fascista, vol. 4, n. 20,

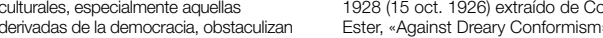 comprender la situación del período. $\quad$ en Aedes, Dawn; Benton, Tim; Elliot, Los estados «democráticos" anteriores David; Boyd White, lan, eds., Art and los años treinta estaban fuertemente admiración por parte importante de segmentos de la sociedad hacia estos regimenes totalitarios.
7 Ghirardo, op. cit., pp. 109-127. mente por cnticos Italianos. Por citar un fascismo, Enaudi, Torino, 1989.}

Terragni tanto en el fascismo como en Mussolini. Sin embargo esto no indica que Terragni debiera ser rechazado por sus creencias políticas. Como con la arquitectura, la continuidad política con regímenes no fascistas debe ser considerada más seriamente ${ }^{6}$.

Por cierto, una lectura más fina de las condiciones políticas y arquitectónicas italianas de los años '20 y '30 nos permite considerar la arquitectura del período como una respuesta a situaciones que eran similares en el resto de Europa, por lo menos para los primeros dos tercios del período fascista. Más detalladamente, muchos de los tópicos principales del fascismo son derivados directamente del Risorgimento, el período culminante en la unificación de Italia, y los períodos previos al nacimiento del fascismo.

Un punto importante de recordar es que el fascismo precedió al nacimiento del movimiento arquitectónico moderno en Italia. Cuando las agitadas discusiones entre las distintas posiciones arquitectónicas emergían, el fascismo estaba ya bien posicionado. El nuevo sistema político clamaba tener respuestas para los problemas sociales y políticos ${ }^{7}$, dentro de los cuales los modernistas pudieron situarse, por lo menos hasta los últimos años del régimen. Moderados y

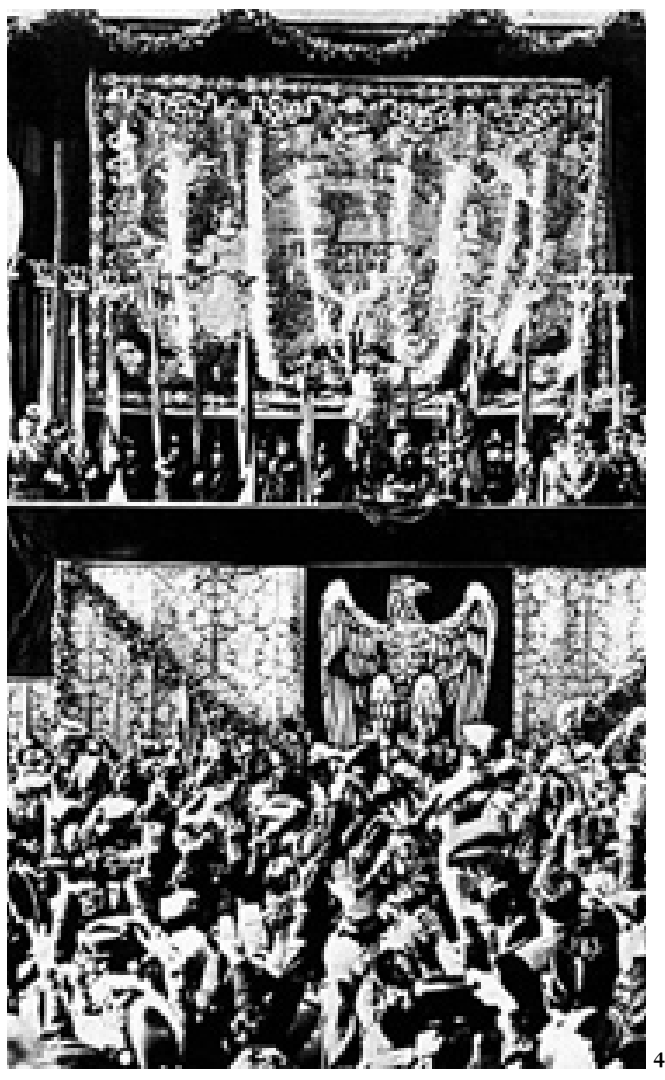

racionalistas sin distinción subscribieron un consenso sobre los objetivos políticos. El objetivo principal era fundar y construir una cultura unitaria organizada políticamente como un estado jerárquico y controlado, desde una tradición regional heterogénea y una realidad política conflictiva. Paradójicamente, era también considerada una "ideología ecléctica" amalgamando fragmentos irreconciliables bajo un nacionalismo exagerado ${ }^{8}$. Sin embargo lo que yacía bajo esta ideología ecléctica puede ser ejemplificado por las palabras pronunciadas por un jerarca hacia fines de 1928: "sólo un pensamiento unitario y una cultura organizada pueden establecer las relaciones y conexiones que son necesarias para dar a las políticas de una clase gobernante una cualidad nacional. Un esquema político grandioso es, fundamentalmente, un simple método de pensar, a través de idear, preparar y organizar la relación entre los valores, tangibles e intangibles, que afectan la vida de una nación; una energía que trae lo particular de vuelta a lo universal determina las cualidades subyacentes de un proceso histórico y crea, en un movimiento abrasivo, un estilo político y el carácter de una era". La transformación de la ciudad de Roma culmina en el diseño de la enorme intervención en la

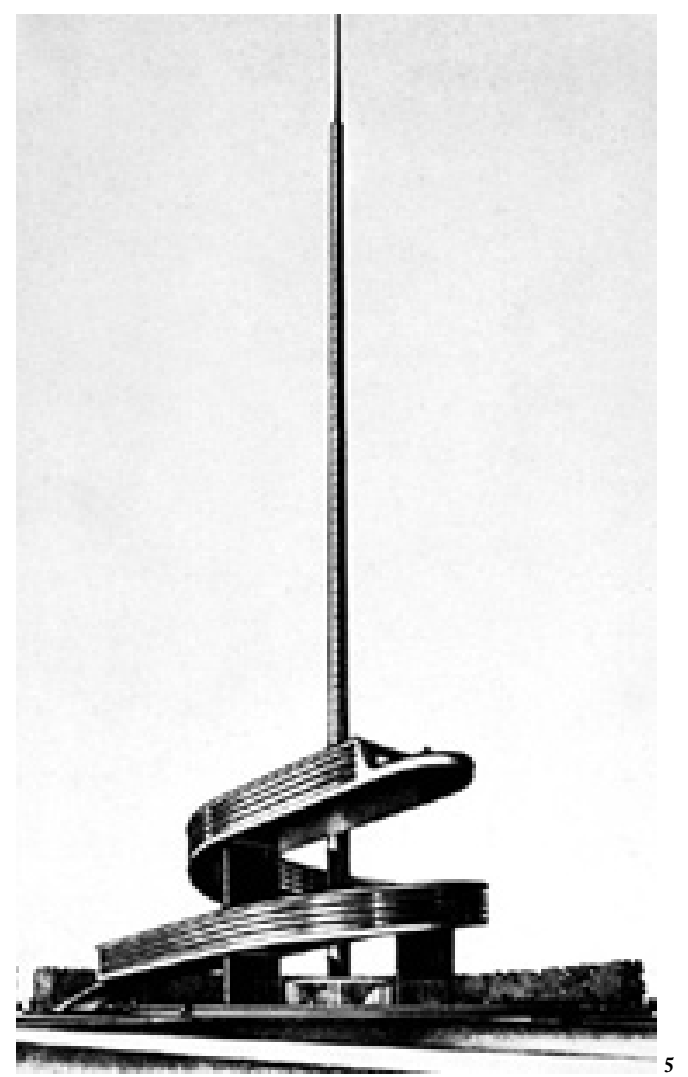

4 Arengario rodeado de

emblemas de la grandeza de Italia, durante manifestació en la Plaza Venecia, Roma 5 Palacio del agua y de la luz, Luigi Nervi
La visión de la historia italiana se difundió en distintos ámbitos: se acentuaba en textos escolares, universitarios y en los investigadores expertos, en las artes, en la arquitectura y en la ciudad. El ejemplo aquí expuesto es un bajorrelieve de tres pisos de altura ubicado en uno de los ingresos de los edificios principales de EUR, el Palazzo degli Uffici.

6 "Historia de Roma a través de sus edificios cívicos", bajorrelieve en el Palazzo degli Uffici (P. Murbiducci)

6a Detalle del Palazzo degli Uffici
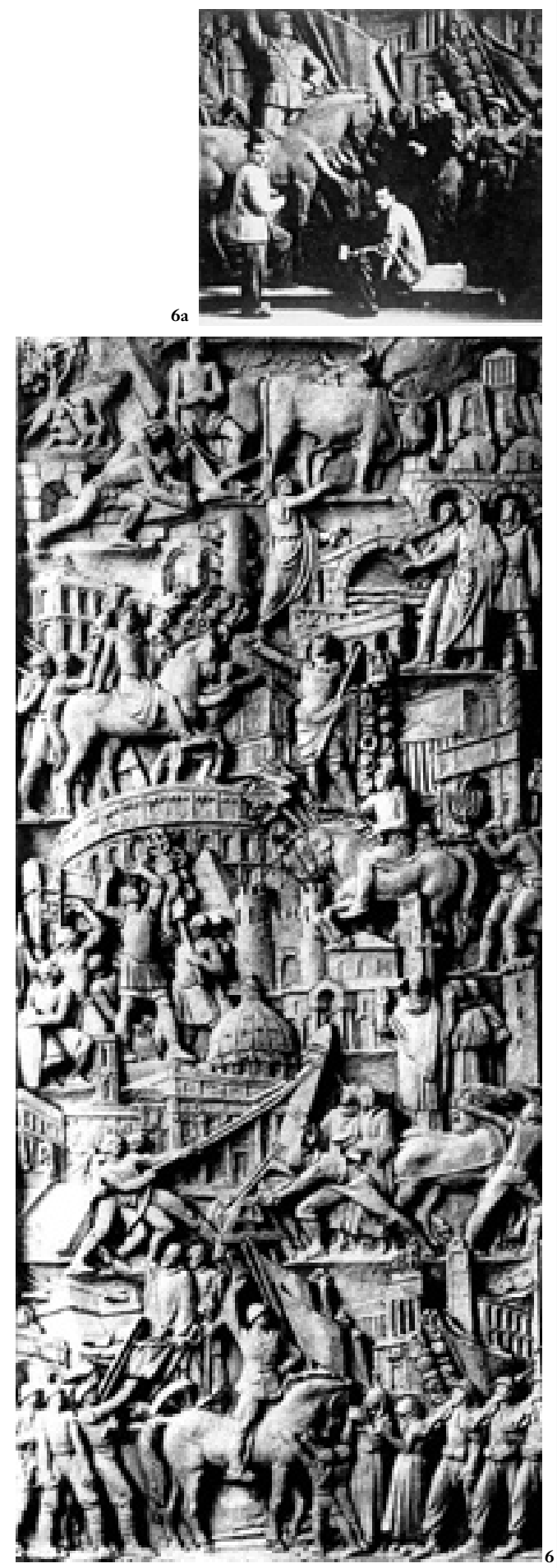
periferia de la nueva "ciudad" de EUR, la cual es el vehículo representativo de tal visión. Ésta se origina en 1935, cuando Italia postula a ser sede de la exposición universal que sigue a aquella de París de 1937 y a la de Nueva York de 1939. El primer diseño fue elaborado durante el primer semestre de 1937. La construcción empezó al año siguiente pero no fue nunca completada para su supuesta inauguración en 1942. En la conceptualización y construcción de EUR participaron intelectuales, políticos profesionales, técnicos y artistas y más de 150 reconocidos arquitectos. Si consideramos la magnitud y el asombroso número de participantes que tomaron parte, un esfuerzo nunca igualado en los años de postguerra, se vuelve difícil descartarlo sólo como un resultado fascista. Por tanto, pareciera que el problema estaría localizado en un estrato cultural más profundo que lo visto hasta ahora.

La historia de la comprensión de la arquitectura fascista desde la guerra demuestra la debilidad del intento de enmarcar el problema solamente dentro de la fisonomía arquitectónica e iconográfica ${ }^{10}$. Primero, la relación de estos problemas con algo como política es indirecto e implícito. Y, segundo, una interpretación que empieza con fisonomía, se encuentra en un territorio siempre de mayor ambigüedad y complejidad, con el resultado que la interpretación se vuelve progresivamente más inestable precisamente donde requiere de mayor estabilidad y continuidad.

Por tanto, la primera interrogante puesta en este escrito es si uno puede identificar los atributos de una búsqueda de unidad en una cultura, formulada a expensas de una continuidad de diferencias. Al estudiar la arquitectura entre las dos guerras mundiales podemos sólo iluminar parte del problema. Esta parte sin embargo no es insignificante, no sólo porque la arquitectura adquirió una importancia singular durante el régimen, sino también, al ser uno de los aspectos más permanentes del campo de la representación, la arquitectura y diseño de la ciudad pueden ser vistos en el esfuerzo de encarnar esas condiciones. Para estos propósitos, sin embargo, la fisonomía arquitectónica en sí misma es demasiado lacónica; debemos tener una concepción más clara de cómo la arquitectura comunica con otros aspectos del programa representacional. Aunque la arquitectura será el énfasis del texto, debe tenerse presente que hay que mirarla excéntricamente, con nuestra atención puesta en aquellos motivos de la cultura en la cual la interpretación del diseño estaba orientada y a la cual contribuyó con sus modos intrínsecos de encarnación.

\section{Parte I}

La primera parte se concentra sobre aquellos aspectos del Risorgimento ${ }^{11}$ que comparten y preparan una cierta base para el fascismo. Estos aspectos incluyen: el fenómeno fundamental no arquitectónico que es el nacionalismo, el intento de fabricar una identidad siguiendo una tendencia del resto de Europa, el ensamblar como cuadro los atributos de una cultura, y la temática misma del Risorgimento: aquella de hacer renacer, literalmente resurgir, una nación. De estas abstracciones a gran escala -nacionalismo, economía, lenguaje, estética, entre otras- la historia tuvo quizás el efecto más pérfido. El proyecto de fabricar una nación de este modo se relaciona con: la decadencia de modos tradicionales de identidad; la emergencia de una cultura y política de masas; y la reciprocidad entre un pensamiento conceptual e historicista y la autoridad de la experiencia individual. La abstracción conceptual del pensamiento está arraigada por una sobredimensión del detalle, que apela a la experiencia individual, enmarcada dentro de la estética, y juntas corresponden al intercambio entre una
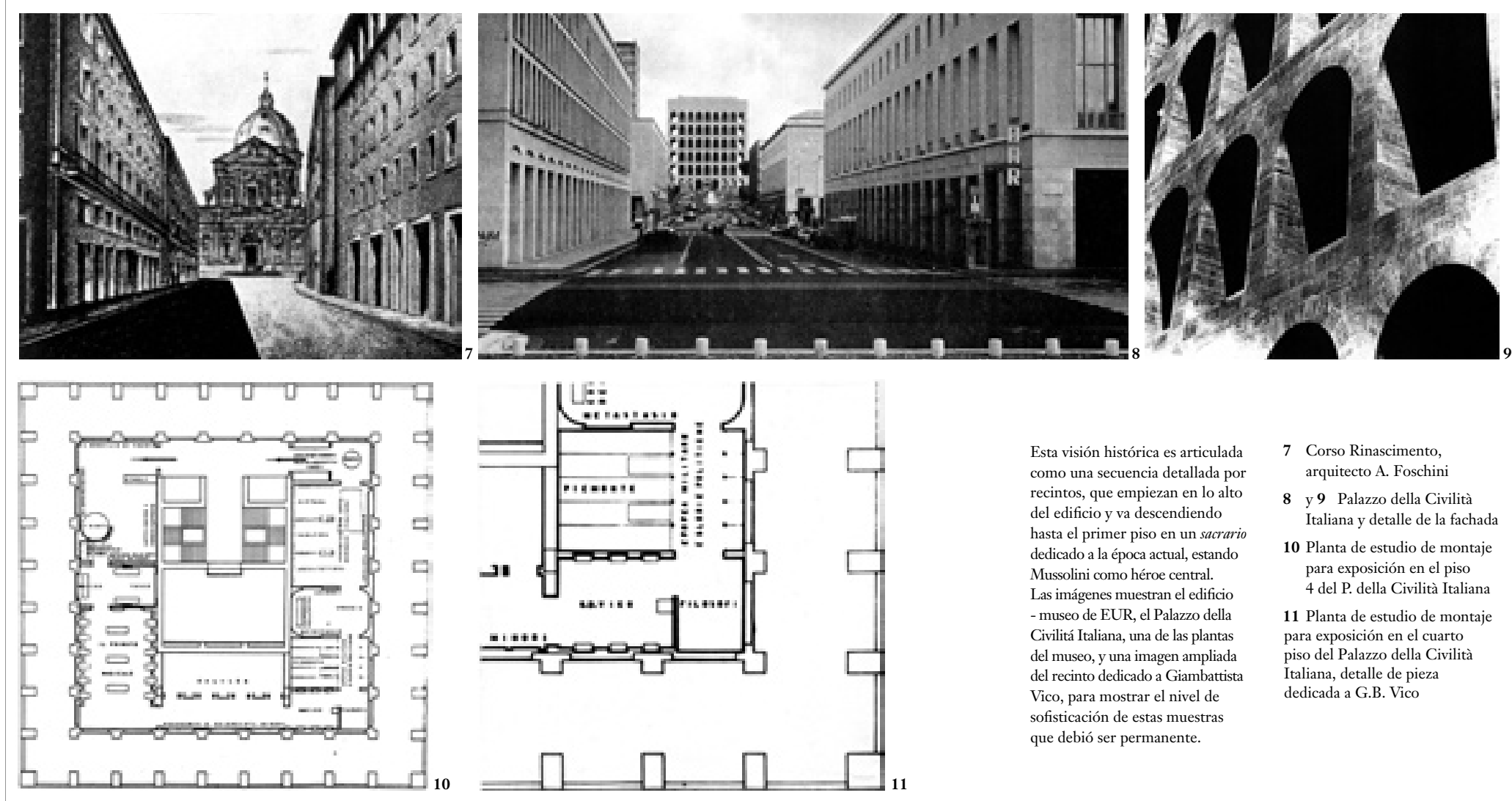

Esta visión histórica es articulada como una secuencia detallada por recintos, que empiezan en lo alto del edificio y va descendiendo hasta el primer piso en un sacrario dedicado a la época actual, estando Mussolini como héroe central. Las imágenes muestran el edificio Las imágenes minestran el edificio - museo de EUR, el Palazzo della
Civilitá Italiana, una de las plantas del museo, y una imagen ampliada del recinto dedicado a Giambattis Vico, para mostrar el nivel de sofisticación de estas muestras que debió ser permanente.
7 Corso Rinascimento, arquitecto A. Foschini

8 y 9 Palazzo della Civilità Italiana y detalle de la fachad

10 Planta de estudio de montaje para exposición en el piso 4 del P. della Civilità Italiana

11 Planta de estudio de montaje para exposición en el cuarto piso del Palazzo della Civilità Italiana, detalle de pieza dedicada a G.B. Vico 
10 Para conocer la amplia bibliografía evolución interpretativa ver prefacio de la tesis.

1 Es el término utilizado par levóa la lar liberación y unificacicón que en 1870

${ }^{12}$ Sacrario era un recinto que a mediados de los treinta se incluía casi $\Theta$ odo edificio de rango institucional. Un la Casa del Fascio de Terragni, entrando al edificio a mano izquierda. Por su fuerte carga polltica emocional han spacios semisacros se originaron antes del fascismo y cómo éste se conviritio en el motivo 13 El términino hege dé la ciudad EUR. sta tesis, no está renco, usado en que le dio el filósofo y político Antonio Gramsci (1891-1937) como cuando plantea una hegemonía cultural de un objetividad radical y una subjetividad radical que aún caracteriza nuestra cultura y que ha sido estudiado por Heidegger.

Con estos antecedentes uno discute en dos territorios arquitectónicos: la actitud hacia Roma (y en particular, los motivos que circunscriben los asuntos de apariencia y significado - estilo) y el espacio del museo, llevándonos al desarrollo de los monumentos conmemorativos y los espacios dedicados a los héroes nacionales, con el surgir del héroe mártir y su celebración última en el sacrario ${ }^{12}$. Esta parte incluye aquellos aspectos de la planificación de Roma con la anticipación de cómo estos planes fueron utilizados por el fascismo.

\section{Parte II}

La segunda parte articula las temáticas de unidad cultural tan deseada por el fascismo. Esto es ejemplificado por los debates sobre Giambattista Vico durante los primeros veinte años del siglo por los trabajos de dos de los más influyentes pensadores del período: Giovanni Gentile y Benedetto Croce.

Junto con muchas otras figuras de la cultura italiana, Vico fue importante para la imagen política del régimen y fue exaltado como un héroe cultural. Por un lado, investigaciones serias, frecuentemente no consideradas, son realizadas por intelectuales de este período. Por otro lado, los resultados de estas investigaciones fueron manipulados para una instrucción popular o derechamente utilizados en propaganda política, especialmente después de los ' 30 , y han sido muy difundidos por estudiosos. Sin embargo, Vico adquiere mucha importancia en la interpretación de Gentile y Croce, quienes lo consideran el filósofo más importante de los últimos doscientos años. En sus extensas investigaciones no sólo lo localizan al centro del interés italiano sino también de la cultura europea. Fueron inmensamente influyentes en la cultura italiana: Croce con sus trabajos sobre estética y su postura de oposición después de sus primeros años de apoyo al régimen; y Gentile con su filosofía, el idealismo absoluto y su irrestricto apoyo intelectual al fascismo. Sin embargo, el punto principal a discutir era que la interpretación de ambos sobre Vico es equívoca. Esta interpretación equívoca, común a muchos intérpretes sobre Vico, resulta del hecho del giro en la comprensión desde el discurso del sensus comunis (la tradición retórica del Vico) a la certeza epistemológica (metodologías post cartesianas, historicismo, esteticismo). Esta desinterpretación subyacente es nombrada en la tesis como narración hegemónica ${ }^{13}$. Esta narración es explotada por el régimen, pero no se origina con él, ni es específica al régimen. Al contrario, esta narración es un elemento fundamental de continuidad antes, durante y después del fascismo, y tiene sus orígenes en el período del Iluminismo.

$\mathrm{El}$ argumento principal es el poder demostrar la crucial diferencia entre unidad (una síntesis conceptual de fragmentos cosificados en la cultura) planteada por Croce y Gentile, a pesar de sus diferencias radicales, exacerbado por el fascismo, y la continuidad (la continuidad se manifiesta sólo dentro de diferencias; necesita encarnarse absolutamente dentro de diferencias significativas en orden de la persistencia de la identidad para tener significado) argumentado por Vico.

\section{Parte III}

Una tercera parte busca demostrar la apropiación fascista de la cultura; cómo esta ambición fue reiterada con una siempre mayor vehemencia y detalle a través de las distintas intervenciones urbanas dentro de la ciudad de Roma, las exhibiciones a gran escala en el casco
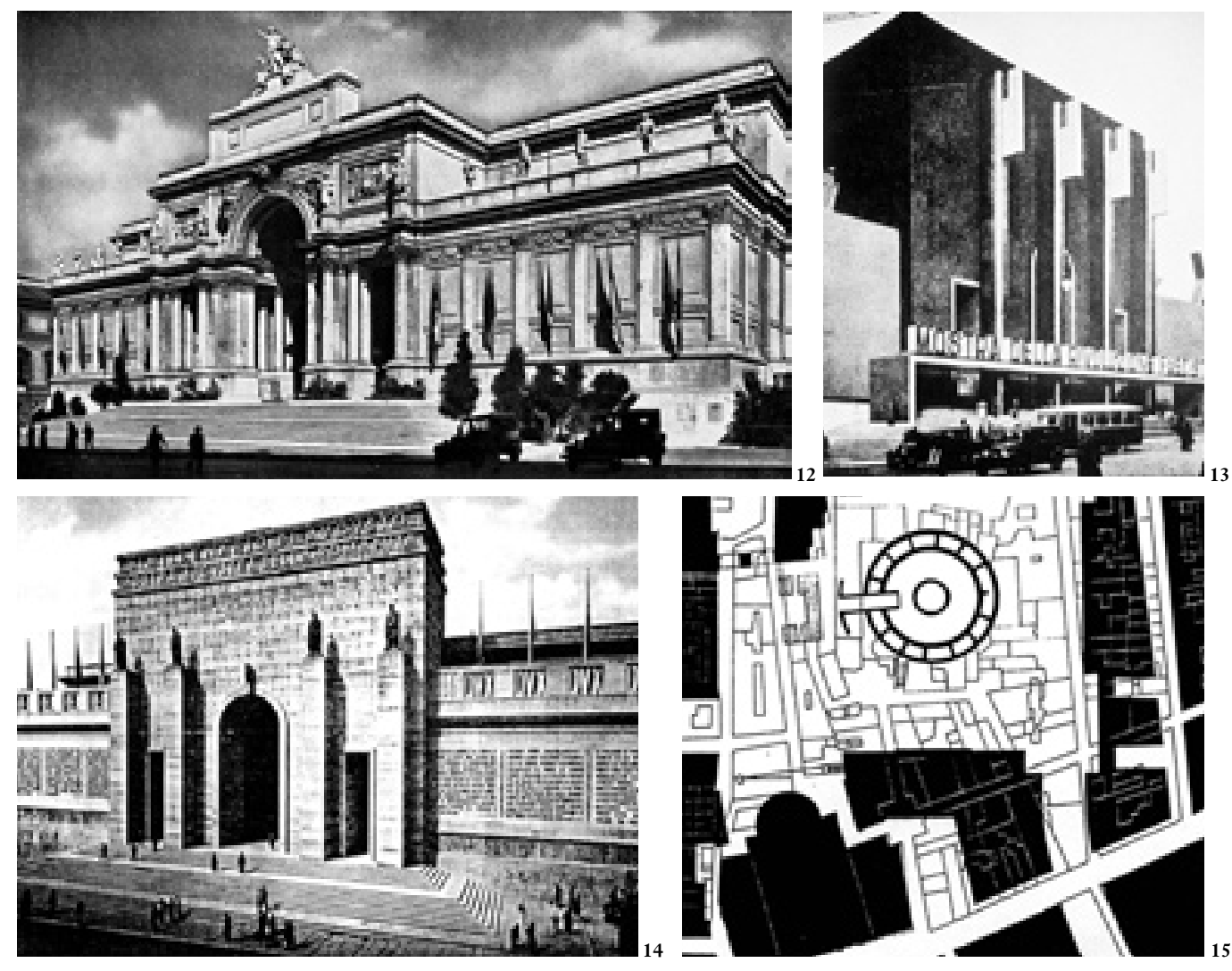
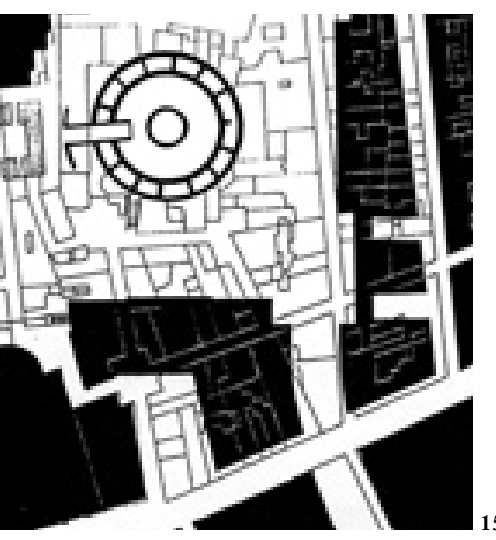

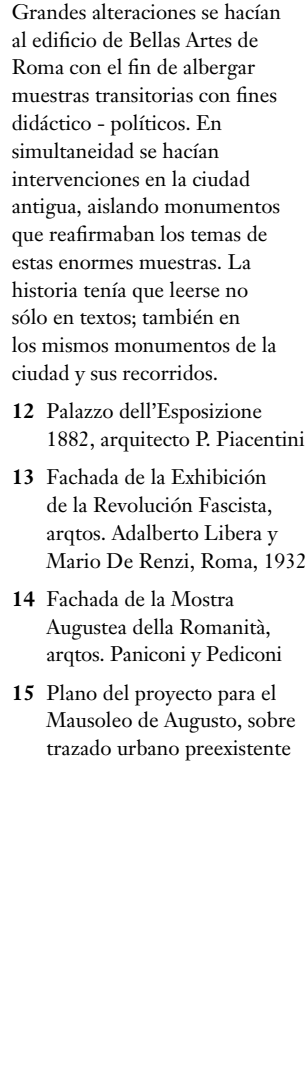


antiguo, y finalmente sintetizadas en la ciudad de EUR, construida como una Feria Universal. En el desarrollo del argumento, la noción de espacio - museo es tomada como el leitmotiv que efectivamente encarna cómo la apropiación de la cultura fue organizada, en cuanto a medios y significado. Se argumenta que el espacio del museo fue utilizado en varias escalas para mostrarlo como una estrategia deliberadamente formulada y progresivamente refinada. Al mismo tiempo, la cultura de museo tenía la intención de ser universal. Lo que estaba siendo formulado al nivel de la ciudad se volvió más explícito con las grandes exhibiciones. La tendencia del espacio museo, de combinar lo didáctico concerniente al contenido del programa cultural junto con el motivo del sacrificio del individuo respecto al total es más claramente manifiesto en el sacrario. Las exhibiciones como espacio de persuasión y como esencia de la visión fascista de una unidad política son descritas y analizadas.

\section{Parte IV}

La cuarta parte es una descripción e interpretación de la ciudad de EUR. Esta nueva ciudad fascista en las afueras de Roma, de igual tamaño al centro histórico, consciente de ser una contraproposición y una síntesis de Roma, suponía proponer muchas soluciones en escalas diversas. Es visto como solución a problemas debatidos desde el Risorgimento. Asume el problema de monumento y ejemplifica las intenciones tipo museo más consistentemente y exhaustivamente que el resto del urbanismo fascista, en parte porque era ella misma un museo, como las otras ferias mundiales. Pero, sobre todo, uno puede observar que al absorber la topografía diferenciada de la ciudad en la ideología espacial enfocada del museo, EUR proponía ejemplificar una escatología cultural como un símbolo exhaustivo, habitable e intramundano.

\section{Conclusión}

La conclusión vuelve al argumento de Vico. Se plantea la cuestión de una cultura dialógica, orientada a la estabilidad, que surge del conflicto e intercambio y es abierta a la historia, en oposición a la visión atemporal de una unidad cultural compuesta por fragmentos enrarecidos de una cultura. Primero, se intentó mostrar que los procedimientos de representación que evolucionaron desde el período postiluminista hicieron posible el arte y la arquitectura cuya reputación ha sobrevivido intacta como aquellos del fascismo. Segundo, este problema es menos observado en el arte y la arquitectura misma y más en las condiciones que promovieron tales trabajos. Esto en parte, porque el arte y la arquitectura eran vistos como sostenedores de un significado moral y político, datándose desde el Romanticismo del s. XVII. Las problemáticas sobre el museo buscaron demostrar cómo fue posible para los fascistas transformar una comprensión dialógica de la cultura en un monólogo, y cuánto de este material para formularlo en proyecto estaba a disposición en la cultura existente. Paradójicamente se discute también cómo este proyecto resultó ser una topografía más dialógica que muchas ofrecidas por el modernismo de democracias liberales que defendían la libertad individual antes y después de la guerra.

\section{Imagen aclaratoria}

Un pasaje corto del libro Cristo se detuvo en Eboli aclara en una imagen la densidad del texto anterior. El autor, Carlo Levi, fue exiliado por el fascismo a Grassano, un pueblo pequeño, en las lejanas y aisladas tierras sureñas italianas. Era un pueblo perdido en cerros de secano, con
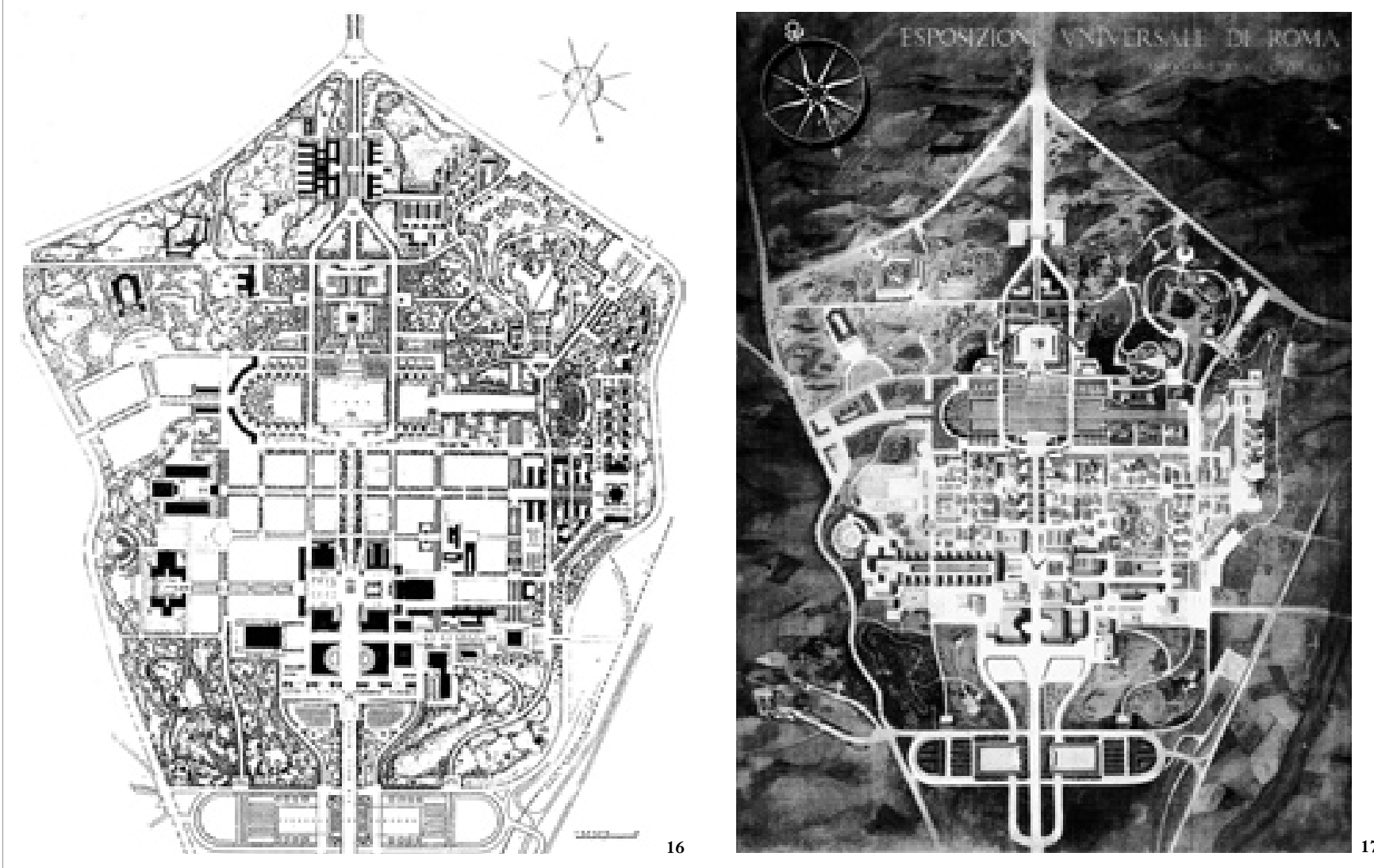

Arte, arquitectura y ciudad buscaban transmitir este mensaje "unitario" y hegemónico. La Roma no permitía una intervención que estuviera al alcance de la visión fascista, si bien ella fue fuertemente transformada. Fue sólo con el
proyecto de la ciudad de EUR, en un paisaje natural (tabula rasa), donde esta visión se pudo consolidar aunque fue sólo parcialmente construido. 16 y 17 Cuarto Plan para el EUR 
costumbres y creencias encarnadas en tradiciones orales alejadas del origen de la así llamada Italia "civilizada". Narra el autor:

"Pasada la plaza, el camino volvía a subir, franqueaba un promontorio y bajaba de nuevo hasta una minúscula plazuela rodeada de casas bajas. En medio de la plaza se elevaba un extraño monumento casi tan alto como las casas, solemne y enorme en la exigüidad del lugar. Era un mingitorio (baño público): el más moderno, suntuoso, monumental mingitorio que pudiera imaginarse. Era como los que sólo se ven desde hace algunos años en las grandes ciudades: de cemento armado. Con cuatro compartimientos y un techo sólido y prominente. En una de sus paredes se destacaba, como un epígrafe, un nombre familiar al corazón de los paisanos: "Casa Rienzi-Turín". Cual extraordinaria circunstancia, qué mago o hada podía haber llevado por los aires, desde las lejanas ciudades del norte, ese maravilloso objeto, para dejarlo caer como meteorito en medio de la plaza de esa aldea, en un lugar en que no hay agua ni instalaciones higiénicas de ninguna especie en centenares de kilómetros. Era la obra del régimen, del podestá Magalone. A juzgar por la mole, debía haber costado muchos años de renta de la comuna de Gagliano. Me asomé a su interior: a un lado, un cerdo estaba bebiendo el agua estancada en el fondo del vaso; en el otro, dos niños empujaban en él barquitos de papel. En todo el curso del año nunca lo he visto usado con otro fin ni frecuentado por seres que no fueran cerdos, perros, gallinas o niños, salvo durante la fiesta de la Madonna, en que los campesinos se encaraman a su techo para disfrutar mejor del espectáculo de los fuegos de artificio. Sólo una persona le dio a veces el uso para el cual estaba construido: esa persona fui yo, que no lo hacía, debo confesarlo, movido por la necesidad sino por la nostalgia" ${ }^{14}$.

El conflicto entre una realidad conceptual y otra concreta, característica que se acentúa desde el Iluminismo, se vuelve manifiesto. La imaginería y las situaciones del régimen inspiran risa, así fue la trágica y humana situación. Lo que la arquitectura italiana representaba política y arquitectónicamente es el intento de substituir un orden simbólico implícito por un orden instrumental explícito. En esto, sin embargo, los esfuerzos sólo demuestran las consecuencias que personas como Le Corbusier hubieran alcanzado -de poderlo realizar- y que fueron impedidos por las circunstancias de hacerlo. ARQ
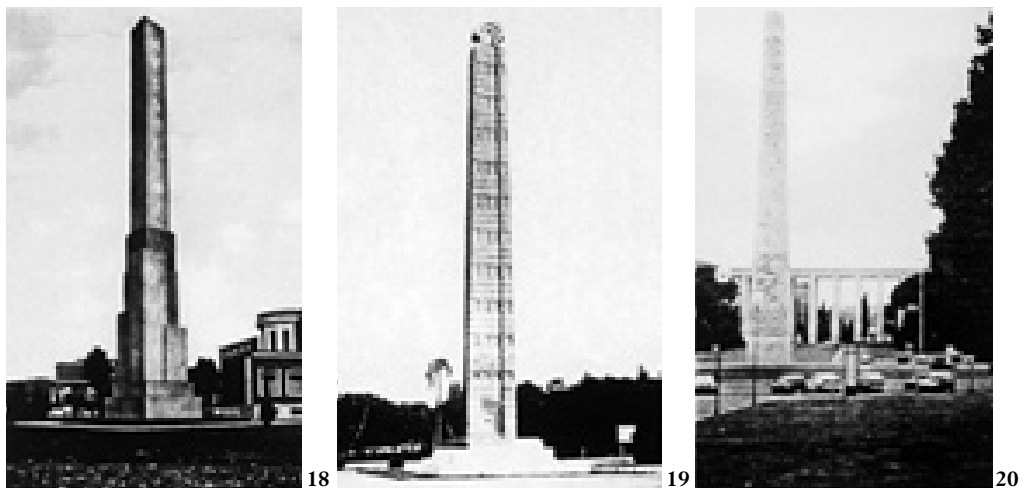

Nota: Para más información sobre las fientes de injacos publicadas, revisar la tesis and Project: The 'City' of EUR, disponible en la biblioteca de la Escuela de Arquitectura de la P.U.C.
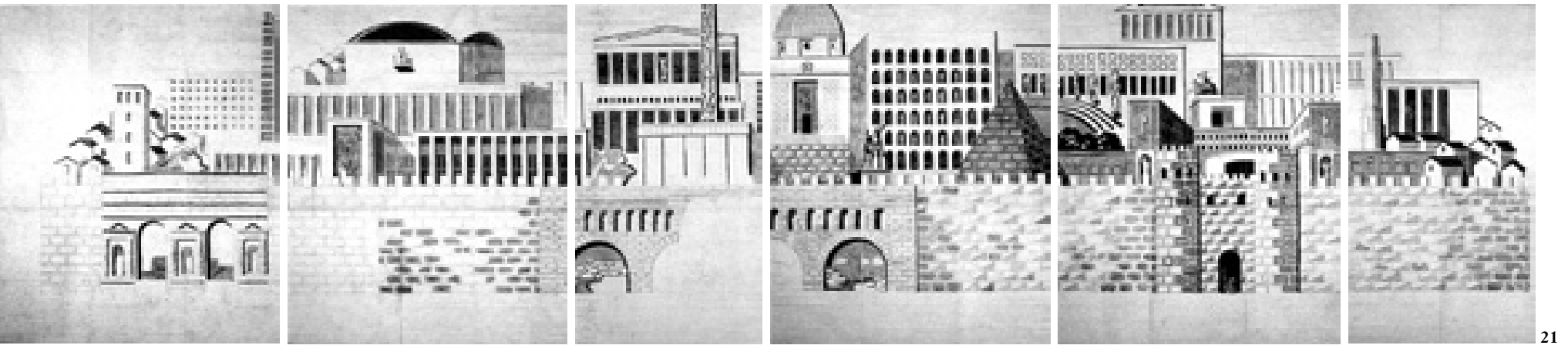